Avaliação das alterações de elementos meteorológicos em Recife-PE no período de 1961 a 2000 Renilson Targino Dantas, Francisca Magnólia de Oliveira, Vanda Maria de Lira, Werônica Meira de Souza

\title{
AVALIAÇÃO DAS ALTERAÇÕES DE ELEMENTOS METEOROLÓGICOS EM RECIFE-PE NO PERÍODO DE 1961 A 2000
}

\section{Evaluation of the meteorological elements variation in Recife - PE in the period from 1961 to 2000}

\author{
Renilson Targino Dantas
}

Prof. Dr. DCA/CCT/UFCG. renilson@ dca.ufcg.edu.br

Francisca Magnólia de Oliveira Doutoranda em Eng. Agrícola do DEAg/CCT/UFCG. magnolia ufcg@ yahoo.com.br

Vanda Maria de Lira Doutoranda em Eng. Agrícola do DEAg/CCT/UFCG. vandalira@yahoo.com.br

Werônica Meira de Souza Mestre em Meteorologia. DEHM/SECTMA/PE

Artigo recebido para publicação em 29/05/2007 e aceito para publicação em 22/02/2008

RESUMO: Neste trabalho foram utilizados dados de precipitação, temperatura e umidade relativa do ar correspondente a um período de 40 anos, compreendido entre 1961 e 2000 no município de Recife-PE, com o objetivo de avaliar as alterações ocorridas nos referidos elementos meteorológicos ao longo desse período. Inicialmente, o período de 40 anos foi distribuído em séries de 10 anos, e, analisados o comportamento dos parâmetros climáticos. Em seguida, foi utilizado o desvio normalizado e o método dos mínimos quadrados para todo o período, e, constatou-se que houve diminuição da precipitação, principalmente na última década (1991-2000) em 247,0 mm, fato que está associado a dois episódios intensos de El Niño ocorrido em 1993 e 1997/1998. Com relação à temperatura do ar, verificou-se um aumento global, em torno de $0,2^{\circ} \mathrm{C}$ nos últimos 40 anos e uma diminuição média mensal da umidade relativa do ar, principalmente na última década.

Palavras-chave: Parâmetros climáticos. Precipitação. Temperatura do ar.

ABSTRACT: In this work, it was utilized rainfall, temperature and relative humidity of the air data of Recife, Pernambuco State, to compute the temporal changes in the referred meteorological parameters since 1961 until 2000. First off all, the 40 years data were distributed in 10 years series, which were analyzed the behavior of the climatic parameters. After that, using the normalized deviations and the method of least squares for all 40 years period, the results indicated that there was a decrease of 247,0 $\mathrm{mm}$ in the precipitation during the last decade in Recife, event that is associated with two intense episodes of El Niño phenomenon during 1993 and 1997/1998. Concerning the air temperature, it was noted a global increase from 0,02\% in the last 40 years and a monthly average decrease of the relative humidity of the air, mainly in the last decade.

Key words: Climatic parameters. Rainfall. Air temperature. 


\section{INTRODUÇÃO}

As características atmosféricas mudam de lugar para lugar e com o decorrer do tempo, em qualquer lugar e em escalas de tempo que variam desde os segundos até centenas de anos. Existem interações importantes dentro da atmosfera, que podem ser resultantes ou mesmo causadoras de tais mudanças. A variabilidade do clima, tanto num mesmo ano como entre anos diferentes, é muito acentuada, e qualquer variação climática pode provocar grandes catástrofes sociais e econômicas.

Na Zona da Mata litorânea, embora haja um decréscimo acentuado de precipitação, existem chuvas em quantidades acima das necessidades, durante cerca de 8 a 11 meses. Landsberg (1981) afirma que existe probabilidade de aumento da precipitação nas cidades que sofrem conseqüências naturais em função do aumento da poluição térmica, da poluição atmosférica, da turbulência e da convecção térmica.

Oke (1987) \& Arya (1988) afirmam que no processo de urbanização, a poluição do ar afeta a transferência de radiação, aumentando o número de núcleos de condensação no ar, e assim propicia aumento da precipitação. A densidade e a geometria dos prédios criam uma superfície rugosa que influenciam a circulação do ar e o transporte de calor de vapor d'água. Os materiais de construção e o asfaltamento das ruas aumentam o armazenamento de calor, e a impermeabilização do solo aumenta a possibilidade de enchentes. Esses fatores, associados a outros, alteram o balanço de energia e favorecem a formação de ilhas de calor. Lombardo (1985) afirma que a poluição do ar e ilhas de calor constituem exemplos importantes das alterações que o processo urbano impõe às condições climáticas locais. A ilha de calor urbana corresponde a uma área na qual a temperatura do ar é mais elevada do que nos seus arredores, o que propicia o surgimento de uma circulação característica do ar. Ao analisar o crescimento de cidades e a degradação da qualidade de vida nas grandes aglomerações dos países de crescimento acelerado, o autor concluiu também que as pessoas se tornam mais vulneráveis às enfermidades cardiovasculares, principalmente as de idade avançada, e que o tamanho cada vez maior das cidades passa a ser inconveniente à população. Munn (1996) explica que uma das causas da formação de ilha de calor nas cidades é a redução da evaporação (pela ausência da vegetação e água disponível); a radiação solar que não é usada na evaporação é conduzida para o aquecimento das ruas, dos edifícios e do ar da cidade.

Os efeitos das variações espacial e temporal na infra-estrutura física e urbana e a vegetação são responsáveis basicamente pelas variações nos efeitos de urbanização sobre a umidade. Entretanto, a redução da cobertura vegetal e a quantidade de vapor retido sobre a superfície são os fatores principais que são responsáveis pela baixa umidade dentro das cidades (CHANGNON, 1969). A tendência de aquecimento observada nos últimos anos, que tem modificado a temperatura média à superfície em escala global e hemisférica, pode estar relacionada com o crescimento urbano ao redor das estações meteorológicas, visto que os efeitos de ilha de calor produzem uma variação na temperatura, similar ao relacionamento com o aumento do efeito estufa dos gases na atmosfera (Kukla et al., 1986).

Stulpnagel et al. (1990) afirmam que as plantas exercem influências positivas no clima da cidade, principalmente no que se refere à temperatura e a umidade relativa do ar.

Sabe-se que o processo de degradação ambiental ocorre de várias maneiras e em vários níveis temporais e espaciais, portanto, a temperatura do ar associada a outros fenômenos como ilha de calor, poluição do ar, chuvas intensas, inundações e desabamentos estão inter-relacionados e devem ser compreendidos por meio do estudo das variabilidades e mudanças de comportamento das diversas variáveis climáticas.

Como resultado das emissões de dióxido de carbono e de outros gases, tem-se falado muito sobre uma prospectiva mudança climática no planeta.

Sociedade \& Natureza, Uberlândia, 20 (1): 67-74, jun. 2008 
Embora não haja certeza de como a biosfera irá responder à acumulação desses gases, grande parte da comunidade científica internacional acredita na elevação do nível dos oceanos. Um aumento médio, entre $1^{\circ}$ e $5^{\circ} \mathrm{C}$, na temperatura do globo é considerada provável de ocorrer nos próximos 50 anos, (CHANG et al., 1992). Ao lado dessa idéia predominante, existe praticamente um consenso de que haverá também uma modificação no regime pluvial em muitas regiões.

As enchentes, ligadas à elevação do nível do mar provocada pela variação climática, seguidas por mudanças na precipitação, podem resultar numa migração humana substancial. As conseqüências mais graves devem ocorrer nas áreas urbanas com grande densidade populacional. Tais conseqüências podem manifestar-se em dificuldades relativas ao abastecimento de água, ao aumento da pressão térmica e às condições que favorecem a disseminação de infecções. As mudanças na precipitação e na temperatura podem alterar radicalmente $\mathrm{o}$ alastramento de doenças transmitidas por vetores, transferindo-as para latitudes mais elevadas, Izrael (1992).

A maior parte do conhecimento atual sobre mudanças climáticas provém dos resultados de experimentos com modelos de circulação geral da atmosfera Canadian Mushroom Growers Association - CMGA, os quais simulam numericamente o comportamento do sistema climático da Terra. Um dos resultados obtidos com a simulação de aumento da concentração de dióxido de carbono $\left(\mathrm{CO}_{2}\right)$ na atmosfera apresentou como conseqüência, um aumento na temperatura média do ar e das áreas desérticas no planeta, incluindo o Nordeste Brasileiro (NEB), Diermeyer \& Shukla (1994).

O objetivo deste trabalho foi estudar as alterações dos elementos meteorológicos (precipitação, temperatura e umidade relativa do ar) no município de Recife, estado de Pernambuco, como forma de identificar as possíveis tendências e ciclos de variabilidade e mudanças no comportamento destes elementos.

\section{MATERIAL E MÉTODOS}

Os dados utilizados, nesse trabalho, referemse a uma série de totais mensais de precipitação, temperatura e umidade relativa do ar, compreendendo o período de 1961 a 2000 da estação de Recife ( $8^{\circ} 03^{\prime}$ $\left.\mathrm{S} ; 34^{\circ} 55^{\prime} \mathrm{W} ; 5 \mathrm{~m}\right)$. As séries utilizadas foram extraídas de um conjunto de dados representativos, cedido pelo Instituto Nacional de Meteorologia (INMET), outra parte, para complementação dos dados, pela Superintendência do Desenvolvimento do Nordeste (SUDENE).

Na avaliação das tendências e suas respectivas retas de regressão da precipitação, do vento à superfície, da temperatura e umidade relativa do ar foi utilizado o desvio normalizado e o método dos mínimos quadrados.

\section{Desvio normalizado}

O desvio normalizado foi obtido pela relação, Moura et al.(1998):

$$
D N=\left(\frac{X-\bar{X}}{\sigma}\right) E
$$

$X=$ valor observado anual do elemento meteorológico (precipitação e temperatura);

$=$ média do elemento meteorológico referente à série de 40 anos (precipitação e temperatura);

$\sigma=$ desvio padrão da série temporal (precipitação e temperatura);

$E=\frac{\sigma}{\bar{X}}$, onde a partir deste erro $(E)$ determina-se quando o ano é considerado normal $(\mathrm{y}= \pm E)$; acima da média $(\mathrm{y}>E)$; muito acima da média $(\mathrm{y}>2 E)$; abaixo da média $(\mathrm{y}<E)$ e muito abaixo da média $(\mathrm{y}<2 E)$.

\section{Método dos mínimos quadrados}

Para evitar o critério individual na construção de retas, parábolas ou outras curvas de ajustamento que se adaptem ao conjunto de dados é necessário instituir uma definição da "melhor reta de 
ajustamento", da "melhor parábola de ajustamento", etc.

A reta de mínimo quadrado que se ajusta ao conjunto de pontos $\left(X_{1}, Y_{1}\right)\left(X_{2}, Y_{2}\right), \ldots . .,\left(X_{\mathrm{N}}, Y_{\mathrm{N}}\right)$ será representada pela equação (Spiegel, 1961):

$$
Y=a \mathrm{o}+a_{1} X
$$

Em que, as constantes $a$ o e $a_{1}$ são determinadas mediante a resolução simultânea do sistema de equações:

$$
\begin{aligned}
& \sum Y=a 0 N+a_{1} \sum X \\
& \sum X Y=a o \sum X+a_{1} \sum X^{2}
\end{aligned}
$$

que são denominadas equações da reta de mínimo quadrado.

As constantes $a o$ e $a_{l}$ da equação (2), se for desejado, podem ser também determinadas por meio das fórmulas: $a o=\frac{\left(\sum Y\right)\left(\sum X^{2}\right)-\left(\sum X\right)(X Y)}{N \sum X^{2}-(X)^{2}}$

\section{RESULTADOS E DISCUSSÕES}

As Figura 1, 2 e 3, representam as médias mensais de 10 anos e as Figuras 4, 5 e 6 os desvios normalizados anuais no período de 1961-2000 da precipitação, temperatura e umidade relativa do ar para Recife.

Na Figura 1, verifica-se grande variabilidade intrasazonal da precipitação existente nos quatros subperíodos estudados. Dos meses considerados mais chuvosos, destaca-se o mês de junho no período de 1961-1970 e o mês de julho na década de 1981-1990, com valores médios de 416,1 $\mathrm{mm}$ e 447,2 $\mathrm{mm}$, respectivamente. De uma maneira geral, observa-se um decréscimo da precipitação no período de 19912000 comparando com os outros períodos.

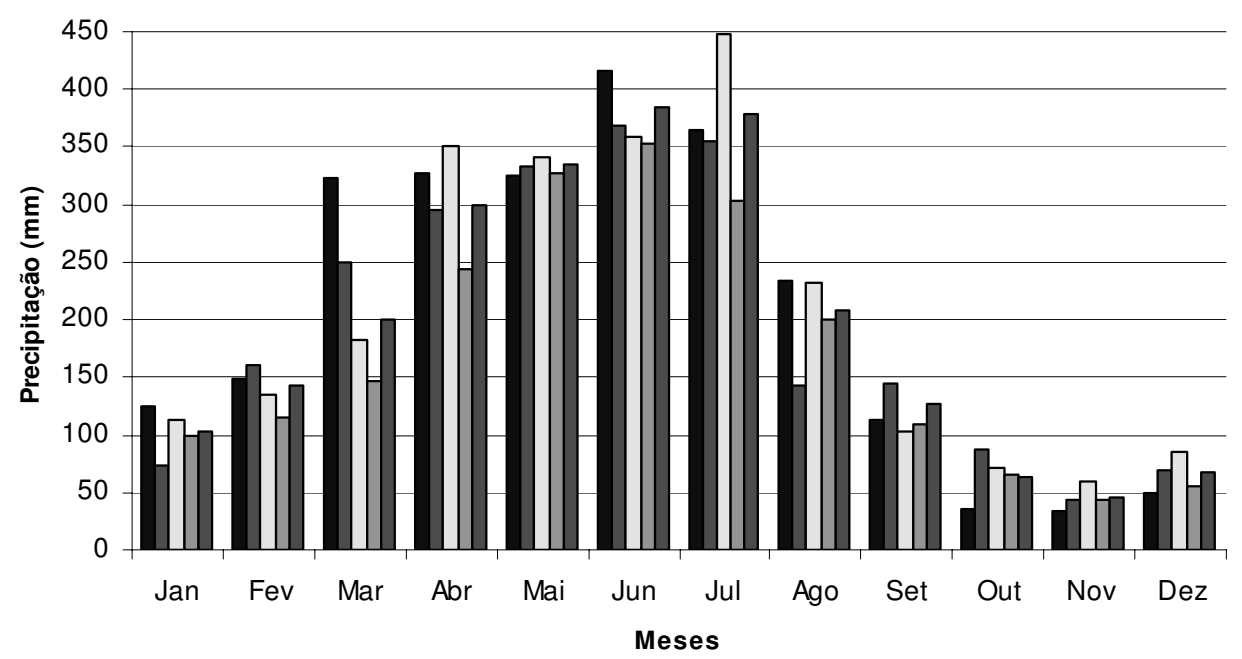

Média 61-70 $\square$ Média 71-80 $\square$ Média 81-90 $\square$ Média 91-00 $\square$ Média Histórica

Figura 1 - Médias mensais da precipitação nos períodos de 1961-1970; 1971-1980; 1981-1990 e 1991-2000 em Recife-PE 
Na Figura 2, observa-se que as temperaturas mais baixas ocorrem principalmente nos meses de julho e agosto, que é considerado o período de inverno para o hemisfério sul, com temperaturas em torno de $24,0^{\circ}$ C. Os maiores valores médios de temperaturas foram registrados na década de 19912000 nos meses de janeiro a março com temperaturas acima de $27,0^{\circ} \mathrm{C}$.

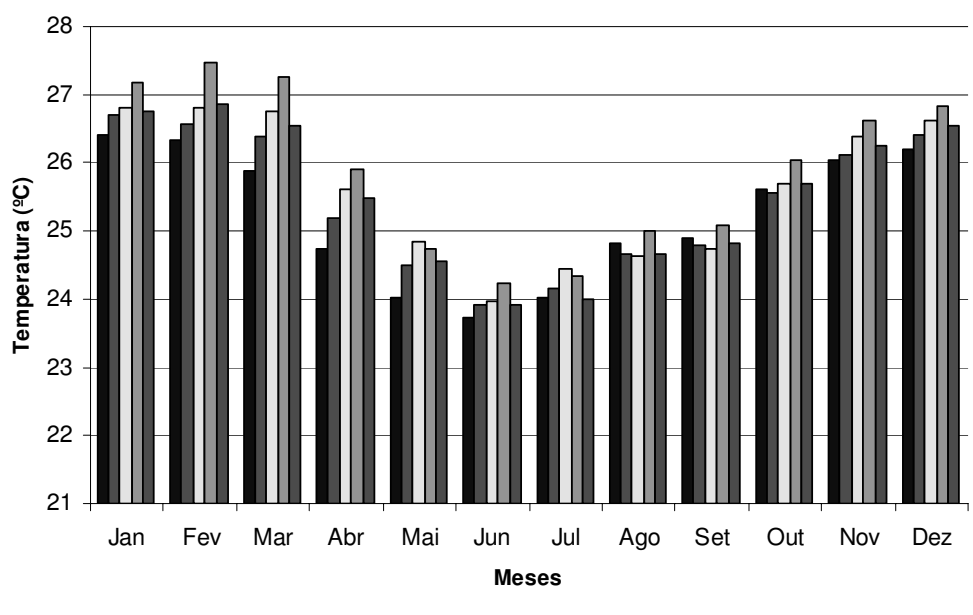

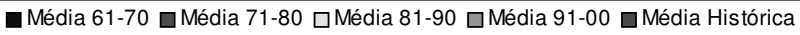

Figura 2 - Médias mensais da temperatura do ar nos períodos de 1961-1970; 1971-1980;

1981-1990 e 1991-2000 em Recife-PE

A umidade relativa do ar é considerada alta, em todos os meses do ano dos quatro períodos estudados com valores acima de $70 \%$, Figura 3. Os maiores valores ocorrem nos meses de maio, junho e julho com valores em torno de $85 \%$, enquanto que os menores são observados em novembro, dezembro e janeiro, próximo a 74\%. Os períodos de 1961-1970 e
1971-1981 apresentaram os maiores valores de umidade, em praticamente todos os meses. Já na última década, nos meses de janeiro a dezembro observam-se os menores valores de umidade relativa comparado com os outros períodos, com exceção para o mês de novembro na década de 1961-1970 que teve um valor menor.

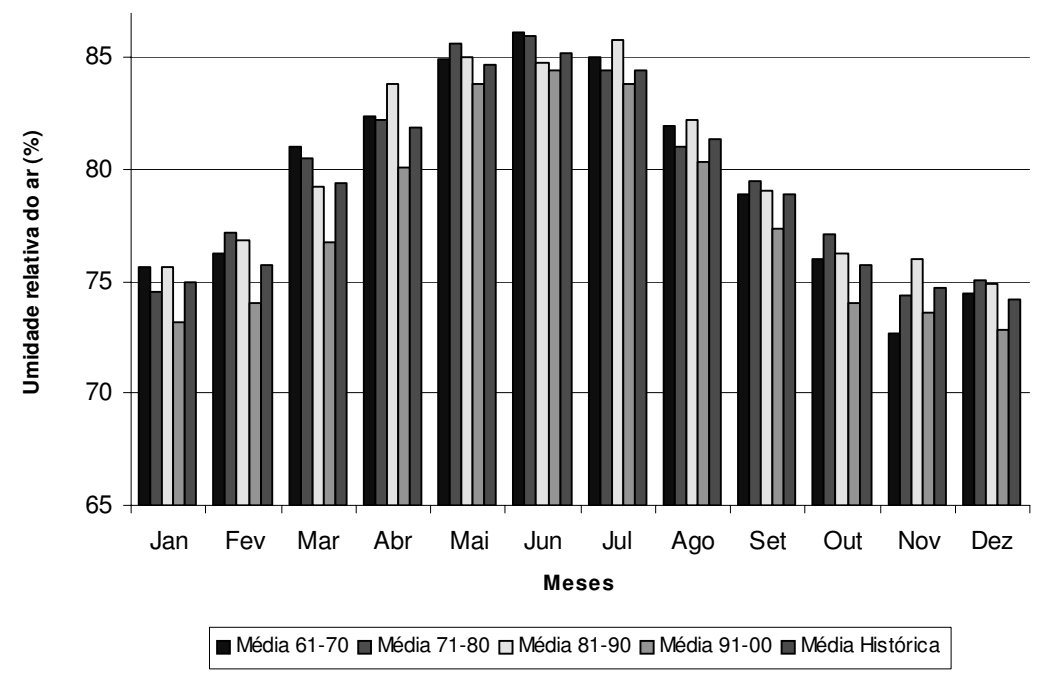

Figura 3 - Médias mensais da umidade relativa do ar nos períodos de 1961-1970; 1971-1980; 1981-1990 e 1991-2000 em Recife-PE 
Na Figura 4 verifica-se grande variabilidade de chuvas de ano para ano, com uma média anual de $2345,5 \mathrm{~mm}$ e um erro calculado em torno de $23,2 \%$, e, os anos de 1970 e 1973 considerados chuvosos com desvios acima de $+23,2 \%$, enquanto que os anos de 1964,1986 e 2000 foram considerados extremamente chuvosos com desvios positivos acima de $+50 \%$, com valores reais de precipitação de $3525,5 \mathrm{~mm}, 3856,8$ $\mathrm{mm}$ e $3482,0 \mathrm{~mm}$, respectivamente; que segundo Lacerda et al.(2000) a atuação de ondas de leste no final do mês de julho e início de agosto de 2000 ocasionou chuvas muito fortes, que praticamente todos os bairros da região metropolitana de Recife ficaram inundados, ocasionando desabamentos, com ocorrência de mortes, além de muitos transtornos para a população e para a defesa civil. Todavia, os anos de 1981 e 1999 foram secos com desvios abaixo de $23 \%$, destacando-se 1993 e 1998 que foram classificados muitos secos, com desvios negativos abaixo de $-44 \%$. Esses anos de seca severa trouxeram grandes problemas para a população, comprometendo as reservas hídricas, e, levando a cidade a um racionamento de oito dias durante muito tempo. Os dados mostram que houve uma redução da precipitação de $-0,24 \%$ nos 40 anos estudados, correspondendo a uma diminuição de $2,3 \mathrm{~mm}$.

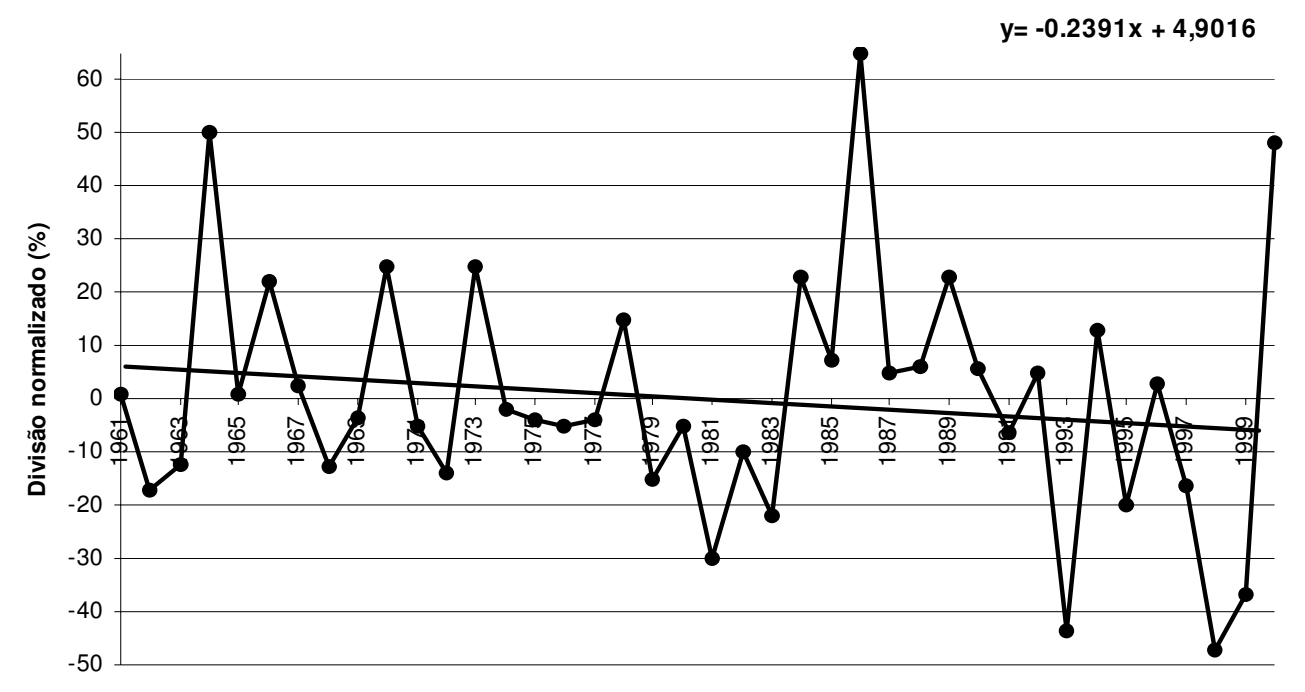

Figura 4 - Desvio normalizado da precipitação anual no período de 1961-2000 para Recife-PE (Média: 2345,52 mm; DP: 545,81; Erro: 23,2\%)

Quanto a temperatura do ar, Figura 5, verificase grande homogeneidade temporal, com valor médio anual de $25,6^{\circ} \mathrm{C}$ e um erro de $1,5 \%$. Os anos de 1973, 1988,1995, 1996 e 1999 apresentaram desvios positivos acima de $1,5 \%$, considerados como temperaturas elevadas, tendo destaque o ano de 1998, com desvio de $+4,2 \%$ e, classificado como um ano extremamente quente com temperatura média próximo a 27,0 C. Os anos de 1962, 1963, 1965, 1968 e 1976 com temperaturas baixas e desvios abaixo de $-1,5 \%$, destacando-se 1961 com desvio de $-3,3 \%$ e temperatura de $24,7^{\circ} \mathrm{C}$, considerado o mais frio dos últimos 40 anos. Observa-se que no período de 19611970 os desvios foram negativos, com as temperaturas mais baixas, enquanto que na década de 1991-2000 apresentou os maiores desvios positivos, exceto para o ano de 1992, com temperaturas mais elevadas. No entanto, pode-se dizer que houve um aumento de temperatura, equivalente a um aquecimento de $0,02^{\circ}$ $\mathrm{C}$, nos últimos 40 anos, tendo sido observada temperaturas mais elevadas na última década, fato que deve estar associado ao aumento significativo das edificações, número de veículos circulando nas ruas e diminuição de áreas verdes. 


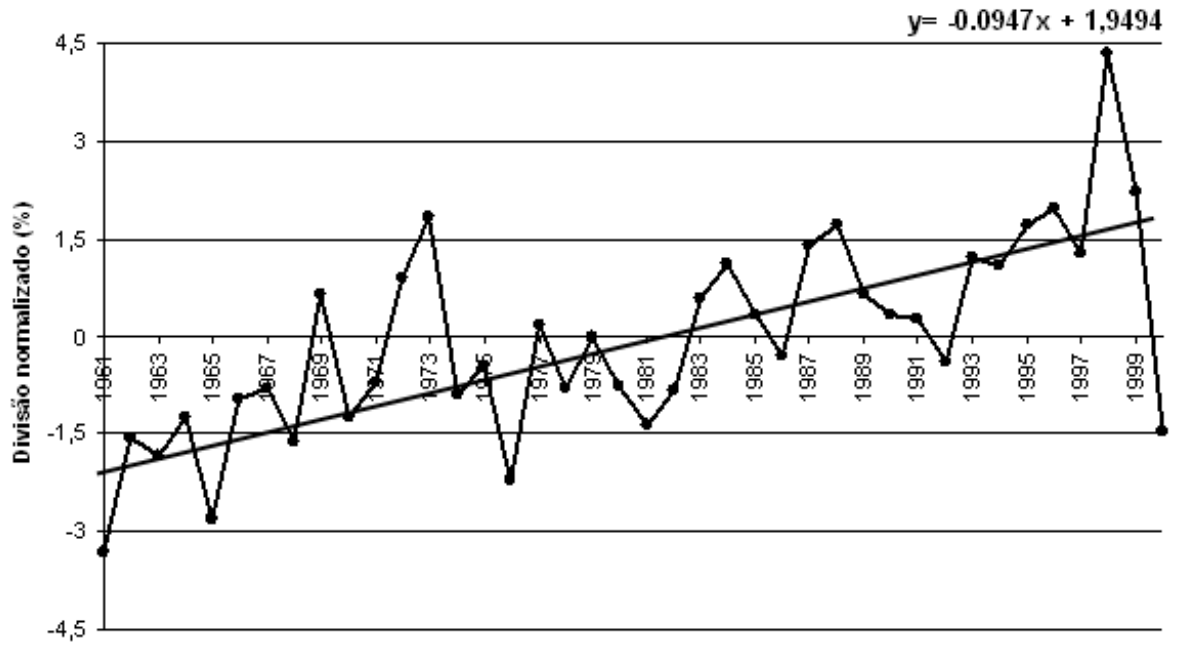

Figuta 5 - Desvio normalizado da temperatura do ar anual no período de 1961-2000 para Recife-PE (Média: 25,6 C; DP: 0,380; Erro: 1,5\%)

Quanto a umidade relativa do ar (UR), observa-se na Figura 6 que não há uma grande variabilidade interanual com relação ao tempo. Em Recife, a UR é considerada alta com média anual de $79,3 \%$, com erro calculado em torno de $\pm 1,7 \%$. Os anos de 1961, 1964, 1986 e 1987 apresentaram desvios acima de $+1,7 \%$, sendo classificados com UR altas, enquanto que 1993 e 1997 com desvios de 1,7\%, destacando-se os anos de 1995, 1998 e 1999 que apresentaram os maiores desvios negativos de $3,7 \%,-4,2 \%$ e $-5,1 \%$, respectivamente, sendo considerados anos com umidade muito baixa. Nessa
Figura, também se observa um período de 13 anos com valores acima e em torno da média histórica (1968-1980). A linha de tendência mostra que houve uma diminuição da umidade relativa do ar próximo a $-0,07 \%$ nos últimos 40 anos, e que na década de 19912000, a UR diminuiu consideravelmente. Changnon (1969) afirma que os efeitos das variações espacial e temporal da infra-estrutura física e urbana, ou seja, que a diminuição de áreas verdes e a quantidade de vapor retido sobre a superfície são os fatores principais responsáveis pela baixa umidade dentro das cidades.

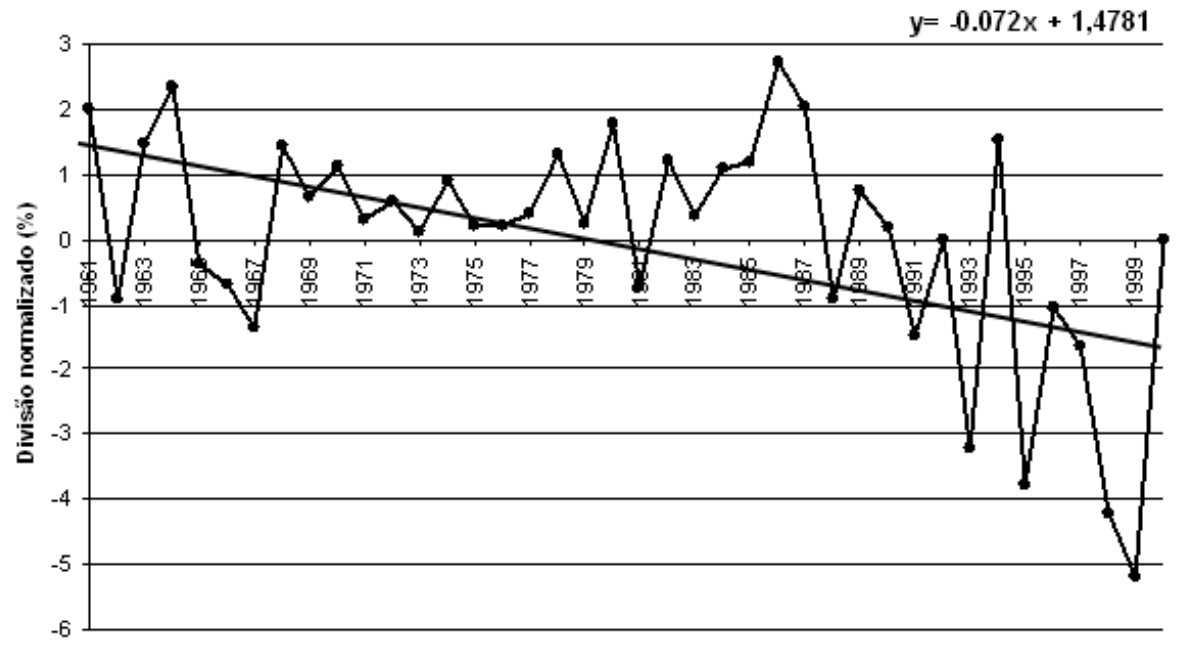

Figura 6 - Desvio normalizado da umidade relativa do ar anual no período de 1961-2000 para Recife-PE (Média: 79,33\%; DP: 1,37; Erro: 1,7\%) 


\section{CONCLUSÕES}

1. Constatou-se diminuição na precipitação média anual na última década (1991-2000) de 247,0 mm em Recife.

2. A temperatura do ar, de um modo geral, aumentou consideravelmente na última década, com valores registrados acima de $27,0^{\circ} \mathrm{C}$.

3. Houve redução da umidade relativa do ar nos últimos 40 anos, principalmente na última década, cuja diminuição foi em torno de $1,5 \%$ pontos percentuais, em relação ao período de 1961-1990.

4. No contexto geral conclui-se que as alterações climáticas ocorridas na última década sofreram influência decorrentes dos dois episódios intensos do fenômeno El Niño, ocorridos nos anos de 1997 e 1998.

\section{REFERÊNCIAS}

ARYA, S.P. Introdution to Micrometeorology. USA: Academic Press Inc, 1988.

CHANG, L.H.; HUNSAKER, T.; DRAVES, J.D. Recent research on effects of climate change on water resources. Water Resources Bulletin. v.28, n.2, American Water Resources Association, April 1991, 1992, p.273-286.

CHANGNON, S.A.J. Recent studies of urban effects on precipitation in United States. Bull.Am.Met.Soc., 50, 1969, p.411-421.

DIERMEYER, P.A.; SHUKLA, J. The effect on climate of doubling deserts. Report N 3. Center for Ocean-Land-Atmosphere Studies - COLA, 1994.

IZRAEL, I.A. Efeitos Econômicos, Sociais e Ambientais de mudanças Climáticas. Desenvolvimento e Meio Ambiente no Semi-Árido: Discursos e Exposições Especiais. Brasília-DF: Fundação Grupo Esquel Brasil, 1992, p. 103-112.

KUKLA G., GAVIN, J.; KARL, T.R. Urban warming. J. Clim. Appl. Meteorol., 25, p.1265-1270, 1986.
LACERDA, F.F. Centro de monitoramento e previsão de tempo e clima-CMPTC. Recife-PE: Projeto apresentado à FINEP/BID, setembro, 1998, $36 \mathrm{p}$.

LANDSBERG, H.E. The urban climate. New York, Academic Press, 1981. 285p.

LOMBARDO, M.A. Ilha de calor nas metrópoles - O exemplo de São Paulo, São Paulo-SP: Editora Hucitec, 1985. 244p.

MOURA, G.B.A.; SOUZA, I.A.; ARAGÃO, J.O.R.; PASSAVANTE, J.Z.O.; LACERDA, F.F.; RODRIGUES, R.S.; FERREIRA, M.A.F. E LACERDA, F.R. Estudo preliminar da variabilidade pluviométrica do setor leste do Nordeste do Brasil: parte I. In: Anais do X Congresso Brasileiro de meteorologia CD ROM, Brasília-DF, 1998.

MUNN, R.E. Descriptive Micrometeorology. Advances in Geophysics. Cidade, Academic Press, 1996, v. I. 199p.

OKE, T.R. Boundary Layer Climates. 2. ed., London; New York: Routlegde, 1987. 435p.

SPIEGEL, M.R. Estatística. Rio de Janeiro, Sedegra - Sociedade Editora e Gráfica Ltda, 1961. 580p.

STULPUNAGEL, A.V., HOBERT, M.; SUKOPP, M. The importance of vegetation for the urban climate. Urban ecology. The Hague: SPB Academic Publishing. 1990, p.175-193.

Sociedade \& Natureza, Uberlândia, 20 (1): 67-74, jun. 2008 